EMITTER International Journal of Engineering Technology ISSN: 2443-1168, Vol. 8, No. 2, December 2020, pp. 442 458

DOI : 10.24003 /emitter.v8i2.585

\title{
An Empirical Research on Pilgrims Wayfinding Satisfaction Study: A Consideration for Improving Wayfinding Experience in Al Masjid Al Haram
}

\author{
Abdullah F. Basiouni \\ Management Sciences Department, Yanbu University College, Saudi Arabia \\ Email: basiounia@rcyci.edu.sa, abasiouni@gmail.com
}

Received September 30, 2020; Revised November 4, 2020; Accepted December 8, 2020

\begin{abstract}
Millions of Muslims visit Makkah Al-Mukarramah every year for Hajj and Umrah. It is a mandatory part of both Hajj and Umrah rituals to visit Al Masjid Al Haram for various activities. Huge crowds and lack of prominent wayfinding signs make Hajis spend more time inside Haram trying to find their way that too in a tense and panicky state of mind. This paper aims at assessing the gravity of wayfinding associated challenges faced by Hajis by applying the well-known Customer Satisfaction Model and proposing possible solutions to minimize potential adverse effects. Convenience sampling was used to collect the data from the proposed sample size of 2000 from various nationalities and regions. A total of 618 responses were received. The structural equation modeling (SEM) method was used for path analysis using AMOS 21 analytical tool and results revealed a reasonable fit between data collected and the model used: chi2 (485.95), chi2 / DF (3.77), RMSEA (0.07), CFI (0.92), and all values of Cronbach's alpha are greater than 0.78 . The results substantiated that Hajis face problems in wayfinding inside Haram, which leads to Hajis finding it challenging to navigate in the Haram area. When the respondents were presented with alternative solutions to improve their wayfinding inside Haram, the results showed a statistically significant improvement in the satisfaction level.
\end{abstract}

Keywords: Wayfinding, CSM, Augmented Reality, Al Masjid Al Haram

\section{INTRODUCTION}

In recent years, $\mathrm{Al}$ Masjid $\mathrm{Al}$ Haram has seen many new developments and constructions covering 356,000 square meters after the last expansion of 2017 [1]. Al Masjid Al Haram is known as the second-largest building in the world after Boeing Everett Factory, the world's largest mosque, and the most expensive building in the world as well [2] and [3]. The Saudi government supported all expansion projects of Al Masjid Al Haram by equally persistent efforts to improve the wayfinding inside Haram [4]. Although these efforts are helping Hajis there still exists room for further improvement in the 
overall experience of Hajis, to meet their expectations. One of those areas for improvement is derived from the combination of huge crowds (i.e., Hajj and Umrah), large and complex constructions and buildings (i.e., Al Masjid Al Haram), wayfinding signage, and the use of augmented reality for wayfinding.

The challenge here is how a visitor to the holy places can find his/her way accurately and shares the address with others to meet or to address an emergency situation. More specifically, in Al Masjid Al Haram, we all noticed and experienced that it is not easy to follow/understand the wayfinding signs whether to meet family members or to reach a specific place inside Haram or simply to find your way out of Al Masjid Al Haram without seeking the help of people, policemen, and some other references such as tall buildings surrounding the Haram or so. Such issues associated with wayfinding, may cause unpleasant consequences for Hajis such as getting panicked or distressed, losing friends and family members, or spend more time and distance to find the missing relative, or find a specific gate to exit Haram. Such hassles may spoil the Haram memories for Hajis.

Further, the Saudi 2030 Vision emphasizes both providing easy access to Haram and increasing the number of visitors to Saudi Arabia in general and specifically for Hajj and Umrah, alongside enhancing diversification and sustainability of the economy [5]. Thus, concerned parties need to further investigate issues related to Hajis' experience in general and specifically to improve the wayfinding signs to better address its intended benefits. Finding solutions to minimize Haram visitors' hassles and challenges will increase their satisfaction which will motivate them to visit Haram again in the future. This research is among the earlier steps to scientifically examine Haram's visitors' satisfaction level on wayfinding signs and propose practical solutions to enhance Hajis navigation experience in Haram.

\section{RELATED WORKS}

There is a continuous dialogue in the literature about the importance of assessing visitors satisfaction level to improve current business services, minimize challenges faced by people while visiting or navigating through large and complex buildings, especially from the perspective of following and understanding wayfinding signs in Al Masjid Al Haram, and the value-added by augmented reality in helping visitors find their ways. The current research joins this dialogue by assessing the usefulness of Haram's wayfinding signs from visitors' perception and whether augmented reality and other simplified options would help in enhancing Haram visitors' wayfinding experience .

\subsection{Visitor Satisfaction}

Customer Satisfaction has always been a central focus of any business operation. It is a leading indicator of performance and a key point for future development in the business. Different administrators, governance, and service providers must pay even greater attention to visitors satisfaction in 
the modern-day environment to assure that they receive proper services [6][9]. Other researchers further associated the improvement in the services provided to visitors by a specific economic sector with an increase in the visitors satisfaction level and consequently a better economic growth [10], [11].

Simply put, satisfied visitors will maintain continuity, loyalty and share a favorable word of mouth to others which are the essential mix for any business owner or decision-maker to maintain successful business operation. For example, a visit to a popular tourist destination, especially an international destination, is quite a complex experience. Visitors may experience satisfaction and dissatisfaction during various phases of their visit and a visitor's overall experience is the sum of the individual experiences that occur during the visitor's trip. These experiences may include interactions with diverse natural, cultural, religious, and constructional attributes and are affected by the visitors' perceptions of service quality, pricing, use of augmented reality (AR) applications, usefulness and intangible self-utility fulfillment [12]-[16]. Similarly, a trip to Al Masjid Al Haram is a very fulfilling and complex experience to explain at the same time. Undertaking such a trip with religious and spiritual motivation makes it even more complex to assess the resultant satisfaction from the visit.

\subsection{Wayfinding Signage}

Wayfinding is a procedure that we go through in our daily life. This procedure can be as easy as shifting from one room to another or as difficult as trying to evacuate a building on fire. In either case, difficulties in wayfinding may aggravate the situation such as lack of time, decreased safety, stress, or discomfort [17]. To reduce those wayfinding troubles that visitors may face, it is critical to recognize how visitors observe elements inside a building.

With the emergence of huge constructions that are above the dimensions of human perception, the need for wayfinding designs and useful signs have significantly increased. Information may be received from various wayfinding support tools such as information booths, signs, and maps, as well as from the architectural and spatial traits of a building [18]. The most common means by which people navigate unfamiliar areas being Static Signage [19]. The static signage in Makkah and Haram also face the issue of having to support a large number of different languages, resulting in increased complexity[20]. It is noticed that pilgrims in Haram always seek help because of this unfamiliar environment and not so useful signs for them [21].

Further, wayfinding signs in Haram appear to be not sufficient in number, not clear, not attractive to visitors, not colored/designed based on zones, and not followed by Haram's visitors [4], [22]. According to the same studies, the design of these signs should attract the attention of visitors to interact naturally with the environment and its sanctity and help the visitors 
to find their way accordingly. It is also suggested that those signs should be categorized in zones and those zones should be directing visitors from one zone to another alongside following the international conventional way of designing such signs, zones, categories.

Although it is universally stated that placing wayfinding signs is an acceptable attempt to prevent people from getting misplaced, it does not always guarantee the desired end result. Visitors can frequently be as lost with the wayfinding signs as they are without them. Typical visitors make fewer incorrect turns in settings with signage than in the ones without [23][25].

Research results recommend that graphic and textual signage may be applied to optimize unique factors of wayfinding. As buildings get larger and more complicated, it turns out to be more difficult to offer simple wayfinding signs and cues if the placed signs and cues ignore the approaches people use and understand the configuration of their surroundings [17].

There is also the effect of other Spatial variables, such as the type of static signage, the distance between different signs, and the overall building structure. These variables have a direct effect on a person's ability to find his way within that structure [24], [26]. In complex surroundings, people find their way by trying to understand what the environment is like and how it is structured. Spatial hints must be found in order to form a mental map of the area. Spatial structures are among the fundamental building blocks of cognitive visualization. Such space structures can be identified by people only if these are distinct, i.e., separated from surrounding areas [19].

Distinguishability may be accomplished by the shape and volume of the building, by using finishes, lighting and colors and graphs, which identify architectural and decorative elements [19].

Moreover, the idea of legibility [27] has had a major impact on architectural planning. Although the architecture itself can include the information to provide wayfinding hints, the spatial design of a structure can provide some areas more suitable for extracting and interpreting information. This capability is known as legibility. The legibility factor is high for a place that makes it easier to obtain and understand environmental information. Added or removed architecture, such as signage, can manipulate a place's legibility.

Even the graphics of signage systems- lettering selection; the contrast produced by the elements of black, white, and color, scale, location and lighting- aid in understanding and, therefore in the understanding of space [18].

\subsection{Augmented reality and large buildings}

Augmented reality (AR) is a technique that overlays some form of spatially registered augmentation onto the physical world. The user can see in real-time the world around him/her, with virtual objects in it. These virtual objects are embedded in the user's world with the help of additional 
features in smart devices. Today the necessary hardware for AR is mostly packaged into one device, such as a high-resolution camera, HD display, GPS, motion sensor, compass and accelerometer. This technology has changed the way people can experience a place of destination by increasing the awareness of one's immediate unknown surroundings [28] and by providing a large amount of easily digestible information to the user [29] all of which cannot possibly be obtained by using only our five senses. Such technologies not only reduce the mental effort required to navigate and discover unknown environments but also provide travelers with complimentary multimedia information about their surroundings.

AR interaction techniques can be further classified into two types [30]. First is the device-centric interactions in which the user interacts with the device and its movement and touches the screen. Second is the natural gesture interactions as in the marker, hand, face, or voice gestures recognition. Based on the potential that AR offers, many large corporations like Google, IBM, Sony and HP are working with many universities to develop it further. Augmented Reality is suitable for applications in almost every subject, especially physics, chemistry, biology, mathematics, history, astronomy, medicine, flight training, project management, and even tourism [31]-[35]. Hence the use of AR can be beneficial in the settings of religious tourism, including pilgrims' visits to Haram. Just like finding points of interest (POI), navigation and receiving information about POIs are the most widely used features in mobile tourism applications [25], [36].

Using AR technologies in wayfinding and navigation applications is not a silver bullet in itself [37]. Despite the fact that the potential of AR has been proven in many previous studies, the effective and usable AR applications are still in their early stages [38]. There are issues related to designing AR applications and adapting this technology in mobile applications. One important issue is AR tracking, which fundamentally affects how users interact with the application. We refer to AR tracking as the method of identifying a user's location and orientation to properly align virtual objects to the real world environment on his smart device. The accuracy of AR applications is critically dependent on the process of locating a user in his/ her environment. The large scale adoption of such technologies by people [39] is another important issue, as some people still use traditional forms of information (i.e., traditional wayfinding signs and land/building marks) to navigate, perhaps due to personal preference for such signs or because of their technophobia .

The literature is short in topics addressing the opportunities of AR in navigating/ wayfinding inside large buildings (i.e., such as $\mathrm{Al}$ Masjid Al Haram) to increase visitors' satisfaction and to make their visit to the destination as pleasant as possible. Also, there is a need to assess and develop solutions as of when the technology can't help (i.e., dead mobile phone battery, no Internet, no mobile application). To fill the gap, this study could be valuable to potential readers. So the objective of this study is to find out 
the effectiveness and application opportunities of AR and non-technology based solutions to facilitate the navigation experience for Haram's visitors and consequently increase their satisfaction.

\section{ORIGINALITY}

There have been many attempts to use visitors' satisfaction measurements to enhance tourist services provided by both the public and private sectors [9], [10]. In addition, discussions about the challenges associated with wayfinding signs in large buildings in general [19] and specifically in Al Masjid Al Haram [4], [22] and the benefits of using augmented reality to enhance visitor experience [25], [40] have already been addressed in the literature. However, no attempts have been made to introduce a combination of augmented reality and wayfinding concepts in large buildings, especially in Al Masjid Al Haram of Makkah Al-Mukarramah, to gauge visitors' experiences from the perspective of assessing visitors' satisfaction. Thus, this paper aims to assess Haram's visitors satisfaction about the current traditional signage system and then propose two solutions to be used when the technology is supported (the use of augmented reality to help Haram visitors navigating inside Haram) and when the technology is not supported (in cases when mobile phone battery is dead, no Internet connection, no mobile application available, lack of technological awareness/skills... etc).

\section{SYSTEM DESIGN}

The research model adopts the well-known customer satisfaction model (CSM) originally developed by Fornell et al. [41] which consists of 15 survey questions to operationalize six constructs. The model causally links the overall customer satisfaction to its preceding constructs, namely perceived quality, customer expectations and perceived value. Customer satisfaction construct also has two proceeding constructs which are customer loyalty and customer complaints, to assure system sustainability by accommodating customer voice for further business development. While all the relationships are positively correlated, the link between the overall customer satisfaction construct and customer complaints/challenges is negatively correlated. CSM was gradually recognized by governments and companies worldwide as a good instrument to measure the responses of a vast amount of people regarding products or service quality. Each country and company modified the original version of the CSM to fulfill their specific requirements and the uniqueness of the measured product or service.

Based on the same model and a step further in the same direction, a new signage system is also hereby proposed to further improve the wayfinding ability of Haram wayfinding signage. This system relies on colors and numbers to let the visitor know his current location with high accuracy. Used in conjunction with an AR-technology-based mobile phone app, this system can provide offline navigation to Hajis. As a first step, it is proposed 
that the pillars of Haram area be used for installing readable signs for an average person, which will help him identify his position inside Haram from where he can take the shortest possible route to his desired destination. To accomplish this, the pillars will be marked with a colored band/ band(s) and numbers. The colors will signify distance from Kaaba and numbers will denote the direction. This will also be helpful for Hajis regardless of the language they speak, see Figure 1 for illustrations.

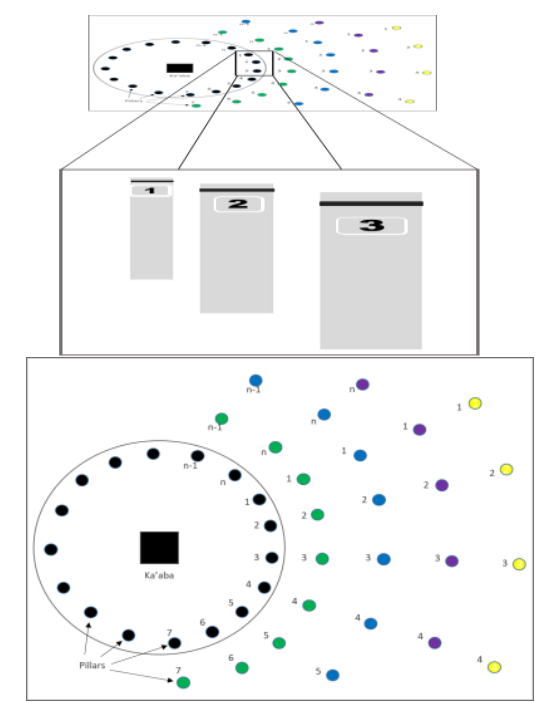

Figure 1. Top and lateral view of deployment pattern

The following aspects must be taken into consideration when deploying these proposed marking:

Numbers: The top of pillars will bear a colored band, followed by a number written on all sides. The number will be in Arabic Numerals $(1,2,3,4, \ldots$.$\left.) and if needed Eastern Arabic numerals can also be used(6) { }_{6} r_{6} r\right)$.

The colored band and the number should be large enough to be visible from a distance of about 50-70 meters, so a person can find out which way the numbers are increasing or decreasing. Pillars in one direction will have the same numbers all the way from Kaabah to the entrance gate of Haram.

Colors: Colors will be a set of basic colors, with no ambiguity among them, like Black, White, Green, Red, Orange, Gold, Purple, Blue, Brown, Yellow, and any other (preferably a set of 10 colors). The base color of the pillar wall will be a decisive factor in choosing the colors.

Level Indicators: As Haram currently has four levels, arrows (or any other appropriate symbol) can be used to indicate level or floor. Basement Ground Floor $\Rightarrow$, First Floor $\mathbf{\imath}$, and Second Floor $\uparrow \uparrow$

The benefits of the proposed solution can be viewed as reducing unnecessary foot-traffic in and around Haram area making it a safer place to visit and worship. This will reduce the number of lost and upset Hajis, making it a 
pleasant Hajj and Umrah experience and a better planned and navigable Hajj and Umrah experience for Hajis.

Then, this solution can be further improved with a mobile phone AR app on the same concept as Google-Lens. This app can make use of a Phone's Camera, GPS, Accelerometer and Compass coupled with Google-Maps. The app could work in an offline mode, thereby not needing internet access which many hajis can not afford. When a Haji will open the app and point his phone towards the static signage (mentioned above), the app will identify the sign and from there it can provide navigation assistance to any desired location, say, Haji's hotel, other places of worship, closest exit, etc. See Figure 2 for App demonstration.
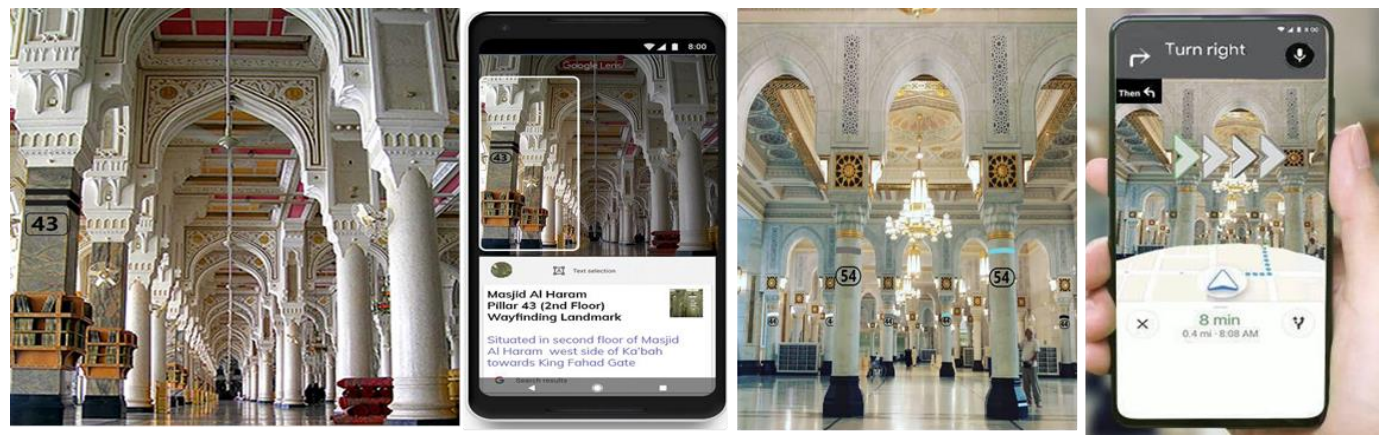

Figure 2. Proposed Static Signage with Mobile Phone

\subsection{Augmented Reality (AR) App}

The remaining of this section will introduce the research constructs as they relate to the research objective to assess Haram's visitors satisfaction for the current signage system based on [41] model. The research hypotheses will follow each completed set of constructs.

\subsection{Visitors Expectations (VE)}

This construct is developed to measure Haram's visitors prediction about the usefulness of Haram's wayfinding signage. This is to capture visitors' prior experience by developing their learning process to expect a future level of performance for a service they will receive, in this case the expected visitor performance in Haram while guided by Haram's wayfinding signs. It is expected that these expectations are cognitive anchors positively correlated with the following perceived performance, perceived quality and visitor satisfaction constructs about Haram wayfinding signs.

\subsection{Perceived Performance (PP)}

The perceived performance meant to assess Haram visitors performance while using Haram's wayfinding signs to navigate within Haram, to tell others to navigate to their current place, or to simply exit the Haram. The basic prediction is that as perceived visitors performance while guided by Haram's wayfinding signs increases, satisfaction as well as perceived quality increases. While perceived performance captures more 
recent experience about wayfinding signs, visitors expectations capture a visitor's prior expectations about the wayfinding signs derived from past experience or based on the word-of-mouth information shared by other visitors.

H1: There is a positive correlation between VE and PP among Haram visitors regarding wayfinding signs.

\subsection{Perceived Quality (PQ)}

This construct assesses Haram wayfinding signs' perceived quality and benefits by visitors. It addresses issues about wayfinding signs characteristics, intended uses and whether following these signs actually helped in finding people and reach places inside haram quickly. It is expected that this construct is positively correlated with visitors satisfaction construct.

H2: There is a positive correlation between VE and PQ among Haram visitors regarding wayfinding signs.

H3: There is a positive correlation between PP and PQ among Haram visitors regarding wayfinding signs.

\subsection{Visitors Satisfaction (VS)}

Visitors satisfaction is the expected result of the visitors expectations, perceived performance and quality [42] of Haram wayfinding signs. Visitor satisfaction is a useful target that can be used by decision-makers to improve services in the future after considering visitors concerns and challenges [43]. The more the visitor's requirements and comments are addressed the more he/she is willing to return in the future (i.e., future behavior intention). Further, the more satisfied the visitors the fewer complaints are generated.

H4: There is a positive correlation between PP and VS among Haram visitors regarding wayfinding signs.

H5: There is a positive correlation between VE and VS among Haram visitors regarding wayfinding signs.

H6: There is a positive correlation between $P Q$ and VS among Haram visitors regarding wayfinding signs.

\subsection{Visitors Signing Challenges (VSC)}

Challenges are negative things about wayfinding signs that made Haram's visitors to be dissatisfied. It is argued that, in general, tourists' overall satisfaction is significantly conditional upon the destination's positive and negative aspects and are important in evaluating the overall visit experiences [44]. While this construct is negatively correlated with the visitors satisfaction construct, it positively impacts the visitors' future intention to return back. Accordingly, an increase in visitors satisfaction should decrease the field challenges and complaints .

H7: There is a negative correlation between VS and VSC among Haram visitors regarding wayfinding signs. 


\subsection{Future Behaviour Intention (FBI)}

Visitor's behavior intention is the behavior of Haram visitors caused future reuse and promotion to use wayfinding signs to others. This construct is the ultimate dependent variable of the research model (i.e., satisfied visitors about wayfinding signs will use and share positive recommendations about his/her experience with the wayfinding signs). That is, satisfied visitors with wayfinding signs will actually use the wayfinding signs in the future and also promote their use to friends, relatives or other potential visitors by acting as free word of mouth advertising agents .

H8: There is a positive correlation between VS and FBI among Haram visitors regarding wayfinding signs.

H9: There is a positive correlation between VSC and FBI among Haram visitors regarding wayfinding signs.

\subsection{Proposed Signing Challenges (PSC)}

This construct is similar to VSC yet it will measure visitors challenges if the proposed signing system is used. It is argued that visitors will have less challenges if proposed solutions are implemented .

H10: There is a negative correlation between VS and PSC among Haram visitors regarding wayfinding signs.

\subsection{New Future Behaviour Intention (NFBI)}

This construct is also similar to the FBI but after exposing the responders to the proposed signing system. It is argued that visitors will be more satisfied to use the proposed solutions and will promote the use of these new proposed signing systems to friends, relatives or other potential visitors. It is also argued that there significant differences among the hypotheses associated with assessing current wayfinding signs challenges and intention to use them (i.e., H7, H8, and H9) against the challenges and intention to use after exposing the responders/visitors to the new proposed signing system (i.e., H10, H11, and H12).

H11: There is a positive correlation between VS and NFBI among Haram visitors regarding wayfinding signs.

H12: There is a positive correlation between PSC and NFBI among Haram visitors regarding wayfinding signs.

H13: There are significant differences between H7-9 and H10-12 to reflect visitors' differences in responses before and after being exposed to the new proposed signing systems.

\section{EXPERIMENT AND ANALYSIS}

Data were collected by questionnaire in the form of numbers and statistics in both Arabic and English languages and based on the developed items by[41]. Most questions were set as statements on a four-point Likert scale, ranging from 1 is "strongly disagreed" to 4 is "strongly agreed". The Survey was delivered directly to Haram visitors using social media 
(WhatsApp, Instagram, Telegram, Facebook, LinkedIn, Researchgate, emails, ...etc.) and then collected from them using google forms. The effective sample of delivered surveys estimated to be 2000 visitors with a response rate of about 30\% (618 returned surveys). Wave analysis tests assess whether and how early responders diverge from late responders. The authors incorporate a wave analysis for the two groups (309 early responders and 309 late responders) the statistical results reveal no significant differences between the two samples.

According to Cronbach's alpha test, all values were greater than 0.78 . Furthermore, all constructs have an average variance explained (AVE) greater than $70 \%$ and all item loadings were at least $0.6-$ a high level of reliability across the model items. All corrected item-total correlation (CITC) values were above 0.4 - a high level of validity of the theoretical constructs explained by the scale items. After conducting SEM analysis, not all paths were found to be significant, see Figure 3 and Table 1. The GOF analysis was also conducted and revealed chi2 (485.95), DF (129), p-value < 0.05, normal chi-square (3.77), the model CFI (0.92), and RMSEA (0.07). Based on the reported results, the study concluded that the model showed a good overall fit.

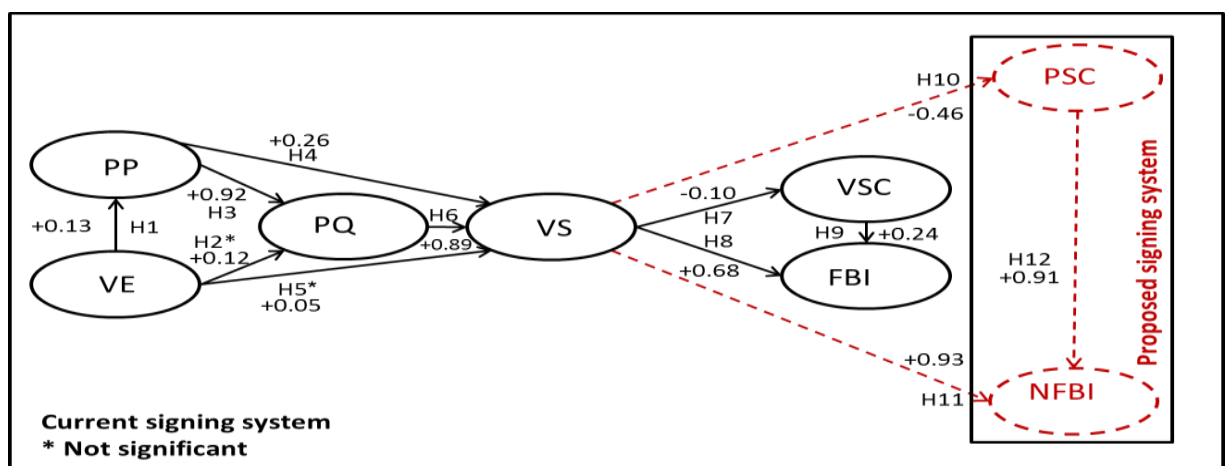

Figure 3. Haram's wayfinding signage visitors satisfaction research model with path coefficients.

The study conducted on Haram's visitors to test their satisfaction levels on the current signage system and the proposed ones. The literature identified that visitors satisfaction is the key to guarantee visitors return and to further develop the services associated with their visiting experience. One of the major challenges that visitors may face is large and complex buildings in which navigation would be an issue of concern. Further, the literature shows that enhanced wayfinding signs and AR may provide solutions for an easier navigation experience for visitors. However, there is a shortage in the literature in addressing challenges that Hajis face during their navigation inside Haram and whether an improvement in the wayfinding signs and the adoption of AR would enhance the level of visitor satisfaction and consequently improving the services provided to Haram's Visitors. 
Table 1. Results of Path Coefficient Analyses and Hypotheses Testing

\begin{tabular}{|c|c|c|c|c|c|c|}
\hline & Path & & Hypothesis & S.E. & $\mathrm{P}$ & State \\
\hline VE & $\ldots>$ & PP & $\mathrm{H} 1$ & .13 & $<0.001$ & Accept \\
\hline VE & $-->$ & $P Q$ & $\mathrm{H} 2$ & .12 & .02 & Reject \\
\hline PP & --> & $P Q$ & $\mathrm{H} 3$ & .92 & $<0.001$ & Accept \\
\hline PP & $-->$ & vs & $\mathrm{H} 4$ & .26 & $<0.001$ & Accept \\
\hline VE & $-->$ & vs & $\mathrm{H} 5$ & .05 & .40 & Reject \\
\hline$P Q$ & $-->$ & vs & $\mathrm{H} 6$ & .89 & $<0.001$ & Accept \\
\hline vs & -->> & VSC & $\mathrm{H} 7$ & -.10 & $<0.001$ & Accept \\
\hline vs & $-->$ & $\mathrm{FBI}$ & $\mathrm{H} 8$ & .68 & $<0.001$ & Accept \\
\hline VSC & $-->$ & $\mathrm{FBI}$ & $\mathrm{H} 9$ & .24 & $<0.001$ & Accept \\
\hline vs & $-->$ & PSC & $\mathrm{H} 10$ & -.46 & $<0.001$ & Accept \\
\hline vs & $-\cdots$ & NFBI & $\mathrm{H} 11$ & .93 & $<0.001$ & Accept \\
\hline \multirow[t]{2}{*}{ PSC } & $-->$ & NFBI & $\mathrm{H} 12$ & .91 & $<0.001$ & Accept \\
\hline & & & $\mathrm{H} 13$ & $\mathrm{H} 7-9$ and & -12 Accepted & Accept \\
\hline
\end{tabular}

The current study reveals all the paths originally theorized were accepted except the ones linking VE with PQ and VS as they were not statistically significant (i.e., H2 and H5). The relationships between VE and both PQ and VS still is significant indirectly through PP and PQ (i.e., H1, H3, and H4) and thus mediating the direct relationships (i.e., H2 and H5). The model also shows that there are significant improvements in visitors experiences when implementing the proposed solutions with a reduction in complaints from $10 \%$ with the current signage system to $46 \%$ reduction in challenges with the proposed solutions. Also, there are significant improvements in the visitors future intention to return back from $68 \%$ to $93 \%$ after comparing visitors responses on the current signage and proposed solutions, confirming H13, see Figure 4. These results are favoring the suggested solutions of using more effective signage in the standalone mode and the AR in the technology-based mode over the currently used signage system. Indeed, Haram visitors are just like any other traveler today, they use modern information software without even noticing that including the use of AR and navigation applications to better understand the surrounding environment.

As such, using handheld devices with embedded AR and navigation systems, visitors can see virtual objects from Haram on top of the real world view of Haram on the screen and consequently understand where they are located and may share their location with others. Such a combination of AR 
with navigation technology would be very beneficial for visitors while exploring unfamiliar places or during their holidays [45]. Also, the use of more efficient signage like the one we are proposing may help in situations of mobile phone's dead battery, Internet connection loss, or no mobile application available or in the case of hajis with limited technological skills.

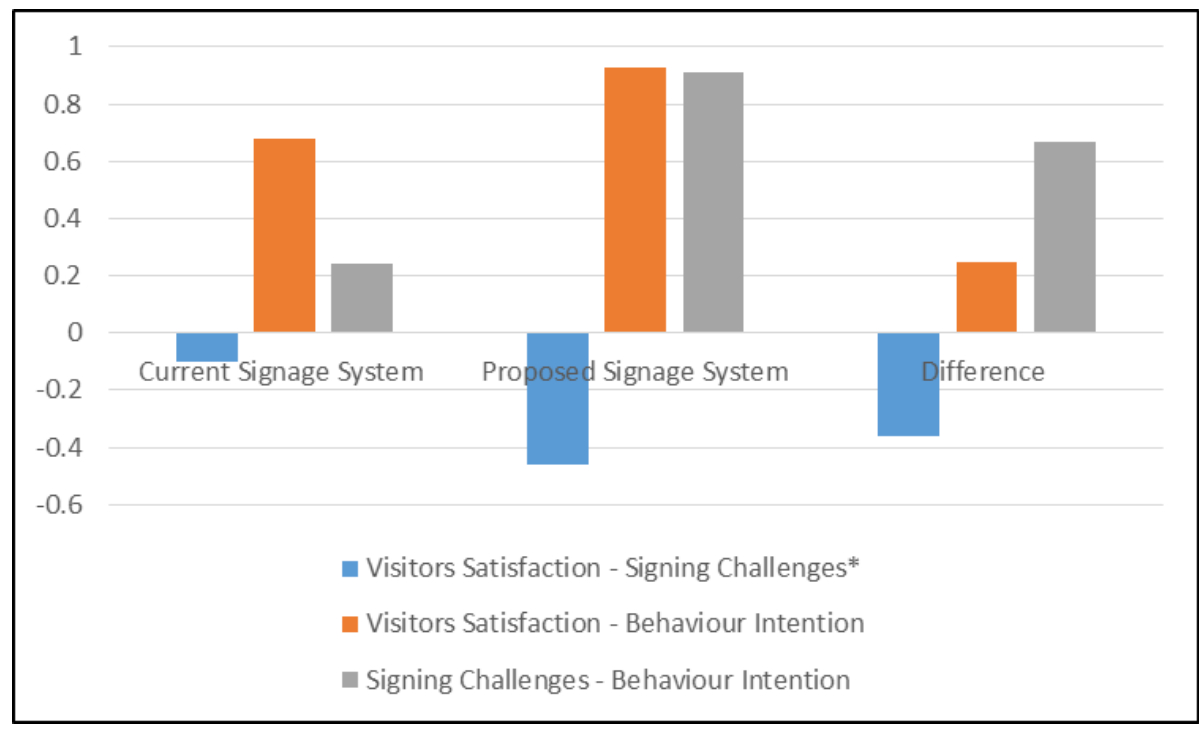

Figure 4. Representation of the increase in satisfaction levels before and after the implementation of the new signing systems.

\section{CONCLUSION}

From a theoretical perspective, this research generally confirms the Customer Satisfaction Model developed by Fornell et al. [41]. This research also contributes to the literature requesting further investigation into the importance of assessing visitors satisfaction to enhance their experience and the development of the services for those visitors. The study also contributes to the literature of wayfinding and AR and how such technology can help in enhancing the wayfinding process and, consequently, the increase in visitors level of satisfaction .

There are a couple of basic lessons learned as a result of this research study. First, Any study of wayfinding in complex buildings and crowded places is naturally complicated and the exact results are difficult to measure. Second, considering a large number of demographic factors (Gender, Age, Ethnicity, Education, Experience..etc) influencing the wayfinding experience, a much larger sample population is required to make an accurate assessment of the effect of existing wayfinding signs for the hajis in Masjid Al-Haram.

Keeping these facts open, the results show that hajis face challenges in specifying their own location and navigating within the masjid, pointing to scope for improvement in the wayfinding system. The study also reveals that having a better wayfinding system will ensure a smooth and steady flow inside Haram and thereby improve the satisfaction of hajis to a great extent 
so as to make their spiritual experience a memorable one and to motivate them to undertake more visits in the future.

This research is proposing a solution that could address the points mentioned above. Considering the great diversity of people visiting the masjid al-haram, usage of universal language such as color \& numbers as wayfinding signs and making them available in most of the places will go a long way in addressing the current wayfinding challenges for hajis in Masjid Al-Haram. The best part of this solution is that it can be used by anyone without any language/educational/cultural/technology barrier which is an ideal solution considering the great diversity of people visiting Masjid AlHaram. Moreover, this solution can complement the technology solutions as well by acting as an input or landmark for the mobile navigation apps using AR technology. In this way, the proposed solution can complete the wayfinding puzzle by being handy in all situations, whether hajis prefer to use technology or not.

In spite of these contributions, however, this research has some limitations. First, the data was collected using electronic social media and electronic surveys. This would be biased to responders with technology skills and may limit the generalizability of the findings. Thus, it is suggested that researchers should target Haram visitors by paper-and-pencil surveys and via interviews for further comparisons as well as assuring validity and reliability. Second, this work is based on single informant responses, so bias in terms of common variance could be significant. Future researchers are advised to split the scale into two scales, of which one represents Haram visitors and the other represents Visitors' agents. This will help in reducing common variance bias as well as increasing our understanding of visitors and agent experience with wayfinding signs. Further, it would be advisable to conduct this study again as a longitudinal study in order to confirm if the results derived from this research model can be extrapolated to other contexts. The future direction may continue in multi-group analysis for these visitors based on gender, age group, and nationality to assess differences and their impacts.

\section{Acknowledgments}

The author of the paper would like to acknowledge the efforts brought by Dr. Akram Nour (Umm Al-Qura University, Makkah Al-Mukarramah, Saudi Arabia), Dr. Samir Alsobhi (Yanbu University College), Dr. Mostafa Sabbagh (King Abdulaziz University), Mr. Bilal Qadir, Mr. Suhaib Varikkodan, Mr. Hafizi Muhamad Ali and Mr. Khaled AL-Massar (Yanbu University College), Dr. Omar Al-Mahdi (King Fahd University of Petroleum \& Minerals KFUPM), Mr. Adnaan S. Varikkodan, and Miss. Hebatuallah A. Basiouni in the conceptual development, data collection, editing, graphical representations, and other supports provided for this study.

\section{REFERENCES}

[1] Ministry of Foreign Affairs, Custodian of the Tow Holy Mosques 
Expansion, $2017 . \quad$ [Online]. Available: http://embassies.mofa.gov.sa/sites/NewZealand/AR/AboutKingdom/ KingdomAchievments/Pages/default.aspx.

[2] Wikipedia, List of largest buildings, 2017. [Online]. Available: https://en.wikipedia.org/wiki/List_of_largest_buildings.

[3] Telegraph, The world's 20 most expensive buildings, Telegraph, $2016 . \quad$ [Online]. Available: https://www.telegraph.co.uk/travel/lists/the-worlds-most-expensivebuildings/masjid-al-haram-mecca-saudi-arabia/.

[4] T. S. Committee, The 19th Scientific Forum of Hajj, Umrah and Madinah Visit Research, in The 19th Scientific Forum of Hajj, Umrah and Madinah Visit Research, 2019.

[5] Saudi Vision 2030, 2016. [Online]. Available: https://www.vision2030.gov.sa/download/file/fid/422. [Accessed: 03-Dec-2019].

[6] M. Möhlmann, Collaborative consumption: Determinants of satisfaction and the likelihood of using a sharing economy option again, J. Consum. Behav., vol. 14, no. 3, pp. 193-207, 2015.

[7] I. Confente, Twenty-five years of word-of-mouth studies: A critical review of tourism research, Int. J. Tour. Res., vol. 17, pp. 613-624, 2015.

[8] L. Sharma, G., \& Baoku, Customer satisfaction in Web 2.0 and information technology development, Inf. Technol. People, vol. 53, pp. 140-147, 2016.

[9] E. Marinao, Mobilities, Tourism and Travel Behavior - Contexts and Boundaries, in Mobilities, Tourism and Travel Behavior - Contexts and Boundaries, 2018.

[10] C. H. Jones, E. and Tang, Tourism SMEs, Service Quality and Destination, London CABI, pp. 15-60, 2005.

[11] T.-Y. Lin, W.-H. Chang, and M.-S. Chen, The International Journal of Organizational Innovation, Int. J. Organ. Innov., vol. 13, no. 1, pp. 165$177,2020$.

[12] M. C. Wang, Y., \& Davidson, Chinese holiday makers' expenditure: Implications for marketing and management, J. Hosp. Mark. Manag., vol. 19, no. 4, pp. 373-396, 2010.

[13] M. Yu, L., \& Goulden, A comparative analysis of international tourists' satisfaction in Mongolia, Tour. Manag., vol. 27, no. 6, pp. 1331-1342, 2006.

[14] R. A. L. Rousan, H. Ibraheim, M. Bader, and N. Khasawneh, Sustainable tourism development in Jordan. Measuring customer satisfaction of american tourists visiting petra and mount nebo in Jordan, $J$. Environ. Manag. Tour., vol. 11, no. 4, pp. 1001-1012, 2020, doi: 10.14505/jemt.v11.4(44).26.

[15] S. Jefferson, L. Jhohana, and C. Danilo, The Augmented reality and virtual reality as a tool to create tourist experiences, Iber. J. Inf. 
Syst. Technol., pp. 87-96, 2020.

[16] V. Navajas-Romero, R. D. Hernández-Rojas, A. Hidalgo-Fernández, and J. A. Jimber Del Rio, Tourist loyalty and mosque tourism: The case of the Mosque-Cathedral in Córdoba (Spain), PLoS One, vol. 15, no. 12, p. e0242866, 2020, doi: 10.1371/journal.pone.0242866.

[17] U. Dogu and F. Erkip, Spatial factors affecting wayfinding and orientation: A case study in a shopping mall, Environ. Behav., vol. 32, no. 6, pp. 731-755, 2000, doi: 10.1177/00139160021972775.

[18] R. Passini, Wayfinding in Architecture. New York: Van Nostrand Rienhold, 1984.

[19] R. Arthur, P., Passini, Wayfinding: People, signs and architecture. New York: McGraw-Hill, 1992.

[20] F. Hamhoum and C. Kray, Supporting pilgrims in navigating densely crowded religious sites. London: Springer-Verlag, 2011.

[21] 0. Almoaid, Hajj crowd management via a mobile augmented reality application: a case of The Hajj event, Saudi Arabia, University of Glasgow, 2015.

[22] A. Basnawi, Signage Marks in the Holy Mosque of Makkah: Analytical Study, Umm Al-Qura University, 2008.

[23] M. J. O' Neill, Effects of signage and floor plan configuration on wayfinding accuracy, Environ. Behav., vol. 23, pp. 555-590, 1991.

[24] A. A. Bindajam and J. Mallick, Impact of the spatial configuration of streets networks on urban growth: A case study of Abha City, Saudi Arabia, Sustain., vol. 12, no. 5, pp. 1-14, 2020, doi: $10.3390 /$ su12051856.

[25] B. Anbaroğlu, İ. B. Coşkun, and H. H. Gürler, WHICH WAY IS ' YILDIZ AMF I' ? AUGMENTED REALITY VS . PAPER MAP ON PEDESTRIAN WAYFINDING, vol. XLIV, no. October, pp. 7-8, 2020.

[26] Y. K. Peponis, J., Zimring, C.,\&Choi, Finding the building in wayfinding, Environ. Behav., vol. 22, pp. 555-590, 1990.

[27] K. Lynch, The image of the city. Cambridge, MA: Harvard University Press, 1960.

[28] W. Chen, Historical Oslo on a handheld device-a mobile augmented reality application, Procedia Comput Sci, vol. 35, pp. 979985, 2014.

[29] C. D. Kourouthanassis P, Boletsis C, Bardaki C, Tourists responses to mobile augmented reality travel guides: the role of emotions on adoption behavior, Pervasive Mob Comput, vol. 18, pp. 71-87, 2015.

[30] T. H. Jung, H. Lee, N. Chung, and M. C. tom Dieck, Cross-cultural differences in adopting mobile augmented reality at cultural heritage tourism sites, Int. J. Contemp. Hosp. Manag., vol. 30, no. 3, pp. 1621-1645, 2018, doi: 10.1108/IJCHM-02-2017-0084.

[31] I. ADASCALITEI and I.-C.-M. BALTOI, The Influence of Augmented Reality in Construction and Integration into Smart City, Inform. Econ., vol. 22, no. 2/2018, pp. 55-67, 2018, doi: 
10.12948/issn14531305/22.2.2018.06.

[32] A. Devereaux, The augmented commons: How augmented reality aids agile self-organization, J. Priv. Enterp., vol. 34, no. 2, pp. 81-101, 2019, doi: 10.2139/ssrn.2956718.

[33] S. G. Fussell and D. Truong, Preliminary results of a study investigating aviation student's intentions to use virtual reality for flight training, Int. J. Aviat. Aeronaut. Aerosp., vol. 7, no. 3, 2020.

[34] C. K. H. Lau, C. F. R. Chui, and N. Au, Examination of the adoption of augmented reality: a VAM approach, Asia Pacific J. Tour. Res., vol. 24, no. 10, pp. 1005-1020, 2019, doi: 10.1080/10941665.2019.1655076.

[35] S. Ahmed, A Review on Using Opportunities of Augmented Reality and Virtual Reality in Construction Project Management, Organ. Technol. Manag. Constr. an Int. J., vol. 11, no. 1, pp. 1839-1852, 2019, doi: 10.2478/otmcj-2018-0012.

[36] T. A. Emmanouilidis C, Koutsiamanis RA, Mobile guides: taxonomy of architectures, context awareness, technologies and applications, $J$ Netw Comput Appl, vol. 36, no. 1, pp. 103-125, 2013.

[37] G. C. Yovcheva Z, Buhalis D, Engineering augmented tourism experiences. Berlin: Springer, 2013.

[38] J. Y. Chung N, Han H, Tourists' intention to visit destination: role of augmented reality applications for heritage site, Comput. Human Behav., vol. 50, no. C, pp. 588-599, 2015.

[39] K. Olsson, T., Lagerstam, E., Kärkkäinen, T., and Väänänen-VainioMattila, Expected user experience of mobile augmented reality services: a user study in the context of shopping centres, Pers. Ubiquitous Comput., vol. 17, no. 2, pp. 287-304, 2013.

[40] A. Han, D.I., Jung, T. and Gibson, Dublin AR: implementing augmented reality in tourism, in Information and Communication Technologies in Tourism, I. Xiang, Z. and Tussyadiah, Ed. Vienna: Springer, 2014, pp. 511-523.

[41] C. Fornell, M. D. Johnson, E. W. Anderson, J. Cha, and B. E. Bryant, The American Customer Satisfaction Index: Nature, purpose, and findings, J. Mark., vol. 60, no. 4, pp. 7-18, 1996, doi: 10.2307/1251898.

[42] C. F. Chen CF, Experience quality, perceived value, satisfaction and behavioral intentions for heritage tourists, Tour. Manag., vol. 31, no. 1, pp. 29-35, 2010.

[43] P. M. D. Stevens P, Knutson B, A tool for measuring service quality in restaurants, Cornell Hotel Restaur. Adm. Q., vol. 36, no. 2, pp. 56-60, 1995.

[44] M. Yoon, Y. and Uysal, An examination of the effects of motivation and satisfaction on destination loyalty: A structural model, Tour. Manag., vol. 26, no. 1, pp. 45-56, 2005.

[45] C. E. Sa DM, Mobile augmented reality: exploring design and prototyping techniques, MobileHCI, pp. 221-230, 2012. 